\title{
IDENTIFICATION OF ENDOPHYTIC BACTERIA FROM Curcuma zedoaria BASED ON PROTEIN PROFILE USING MALDI-TOF MASS SPECTROMETRY
}

\author{
TRI RATNA SULISTIYANI ${ }^{1 *}$ and PUSPITA LISDIYANTI ${ }^{2}$ \\ 'Research Center for Biology, Indonesian Institute of Sciences (LIPI), Cibinong Science Center, Bogor 16911, Indonesia \\ ${ }^{2}$ Research Center for Biotechnology, Indonesian Institute of Sciences (LIPI), Cibinong Science Center, Bogor 16911, Indonesia
}

Received 30 December 2016 / Accepted 06 October 2017

\begin{abstract}
Valid identification of microorganisms is a vital information to establish culture collections. Currently, molecular approach based on $16 \mathrm{~S} \mathrm{rDNA}$ is widely used for bacterial identification. This approach is however, time consuming and expensive. Matrix assisted laser desorption ionization time of flight mass spectrometry (MALDI-TOF MS) allows the identification of microorganisms directly from colonies and it only takes some few minutes. The interest of this study was to identify endophytic bacteria associated with Curcuma zedoaria based on protein profile using MALDI-TOF MS system and compare with $16 \mathrm{~S}$ rDNA sequence results. Endophytic bacteria were isolated from part of medicinal plant C. zedoaria collected from Bogor, West Java Indonesia. The identification of selected bacteria was performed by protein profile using MALDI-TOF MS. A total of 66 endophytic bacteria from C. zedoaria plant, were selected for identification. The result of MALDI-TOF MS analysis showed that eleven isolates $(16.67 \%)$ were correctly identified to the species level and 23 isolates $(34.85 \%)$ matched on genus level of molecular approach. These results demonstrates that the MALDI-TOF system is suitable and feasible approach for the bacterial identification, mainly for screening and grouping of large number isolates.
\end{abstract}

Keywords: Curcuma zedoaria, endophytic bacteria, identification, MALDI-TOF MS

\section{INTRODUCTION}

Rapid and accurate identification of bacterial isolates has crucial role in the culture collections. Several methods of identification have been developed. Bacterial identification is predominantly based on phenotypic, morphological (Gram-positive and negative) and biochemical properties testing analysis. However, classification and identification by these methods can be difficult because of variations in phenotypic characteristics, time-consuming and laborius (Seng et al. 2009; Rychert et al. 2013). Several years ago, molecular identification based on nucleotide sequencing of ribosomal DNA (rDNA) sequence analysis could replace the phenotypic, morphological and biochemical characteristics for identification of microorganisms to genus level (Rajendhran \& Gunasekaran 2011). Molecular approach based

* Corresponding author: trilisty01@gmail.com on rDNA sequence have widely been used for identification of procaryotic taxa. The $16 \mathrm{~S}$ rDNA sequences has confirmed the representativeness of the sequence in bacterial phylogeny (Woo et al. 2008). However this method is not suitable for a preliminary screening and grouping of large numbers of isolates in environmental and clinical microbiology laboratories.

Analysis based on protein profile present in bacterial cells using Matrix Assisted Laser Desorption Ionization Time of Flight Mass Spectrometry (MALDI-TOF MS) is becoming feasible and precise for bacterial identification (Bizzini et al. 2011; Santos et al. 2013). MALDITOF MS allows rapid identification of bacteria, less expensive on operational cost, accurate and low sample volume requirements compared to molecular approach (Wunschel et al. 2005; Singhal et al. 2015). It can be performed as soon as colonies are isolated and can be done just in a few minutes (Eigner et al. 2009; Seng et al. 2009; Neville et al. 2011; Rychert et al. 2013; Jamal et al. 2014). 
MALDI-TOF MS analysis was done by comparing the MALDI-TOF MS spectra or protein profile "fingerprints" obtained from bacterial cells to a library from proteomic database (Martiny et al. 2012; Guo et al. 2014). Protein profile are significantly different for each bacteria and it contain certain unique mass marker even over the small mass range detected. Each bacteria shows signature characteristic peaks that are distinct for species level (Cain et al. 1994). The identification of microorganisms by MALDITOF MS is based on the detection of mass signals from biomarkers that are specific at genus, species or sub-group level (Ferroni et al. 2010; Benagli et al. 2012), therefore changes in protein profiles would be easily identified. The protein profile from each bacteria can serve as unique information for bacteria chemotaxonomic marker, for example to differentiate closely related species, also could enriche the information contained in procaryotic protein sequence databases. Kudirkiene et al. (2015) reported that MALDI-TOF MS was succesfully used in sub-species identification of Streptococcus equi.

Using MALDI-TOF MS, routine bacterial identification can be obtained much earlier than identification by molecular and conventional methods. Therefore, this technique can be used as quality control management of cultures deposited in Culture Collections. The main objective of the study was to evaluate the identification of endophytic bacteria associated with $C$. zedoaria based on protein profile using MALDI-TOF MS system compared with the results based on 16S rDNA sequence from previous study (Sulistiyani etal. 2014).

\section{MATERIALS AND METHODS}

\section{Bacterial Strains}

A total of 66 endophytic bacteria isolates from Biosystematic and Culture Collections Laboratory-Research Center for Biology, LIPI, was used to evaluate the MALDI-TOF MS analysis were recovered from previous study (Sulistiyani et al. 2014). The isolates were preserved in $10 \%$ glycerol stock at $-80^{\circ} \mathrm{C}$. The bacteria were grown using Nutrient Agar (NA) media. The bacteria isolates were from $C$. zedoaria (white turmeric) planted in 3 areas in Bogor, Indonesia, in 2013. The plants materials collected from private garden in Bojong Gede (BG), experiment garden of Research Center for Biology, Indonesian Institute of Sciences, Cibinong $(\mathrm{CBN})$ and garden of medicinal plants collection of Biopharmaca Research Center, Bogor Agricultural University, Dramaga (DRMG). All bacteria were previously identified by molecular identification based on $16 \mathrm{~S}$ rDNA sequence. The bacteria represented 23 genera and 46 species (Sulistiyani et al. 2014).

\section{Preparation of Bacterial Cell Extracts}

Bacterial isolates were cultured from glycerol stock on Nutrient Agar (NA) and incubated under standard conditions at $35-37^{\circ} \mathrm{C}$ for 48 hours and subcultured twice to ensure all isolates were in the same physiological state. Cell extract was prepared by picking a single colony of a fresh culture and suspended in $20 \mu \mathrm{L}$ formic acid of $25 \%$ concentration and then mixed until complete suspension is formed by vortex. The extract was sonicated for $10 \mathrm{~min}$ and spinned to get the supernatant. Finally, the supernatant was used for MALDI-TOF analysis.

\section{MALDI-TOF Analysis}

The bacterial cell extract of $0.5 \mu \mathrm{L}$ was placed in duplicates onto a steel target plate and allowed to dry at room temperature. Each sample was overlaid with $1 \mu \mathrm{L}$ matrix of $\alpha$-cyano-4hydroxycinnamic acid (CHCA) in ethanol : acetonitrile : water : trifluoroacetic acid. The sample and matrix were mixed thoroughly and air dried at room temperature. Measurements were taken using a MALDI-TOF MS Axima system (Microbiology Laboratory of the Mulhouse Hospital, France). The laser frequency was $50 \mathrm{~Hz}$, the acceleration voltage was $20 \mathrm{kV}$, and the extraction delay time was 200 ns. Each spectrum resulted from 5 laser shots at 100 random positions within measuring spot. The spectra were recorded in the linear positive mode within a mass range of 2 to $20 \mathrm{kDa}$. All mass fingerprints were analyzed by the SARAMIS software, which first compares them to the superspectra and in a second step to the individual spectra of the database using AnagnosTec version 4.07 (Axima system manual). 


\section{Calibration and Validation Analysis}

The instrument was calibrated and validated using a control strain of Escherichia coli K12 InaCC B5. Several strain were also used for quality control including of Bacillus substilis InaCC B1, Pseudomonas aeruginosa InaCC B3 and Staphylococcus aureus InaCC B4.

\section{RESULTS AND DISCUSSION}

Accurate identification of bacteria could be obtained from several identification methods, such as morphologic, phenotypic, physiologic and molecular methods. However, as mentioned earlier, these methods are not suitable for a preliminary screening and grouping of large numbers of isolates from environmental and clinical samples and also, for controlling the identity and purity of microbial cultures preserved in Culture Collections. To overcome these problems, the present study evaluated the capability of MALDI-TOF MS for species identification of microorganisms such as bacteria isolates. Validity of MALDI-TOF MS results was compared with the results of molecular identification based on $16 \mathrm{~S}$ rDNA sequences as a

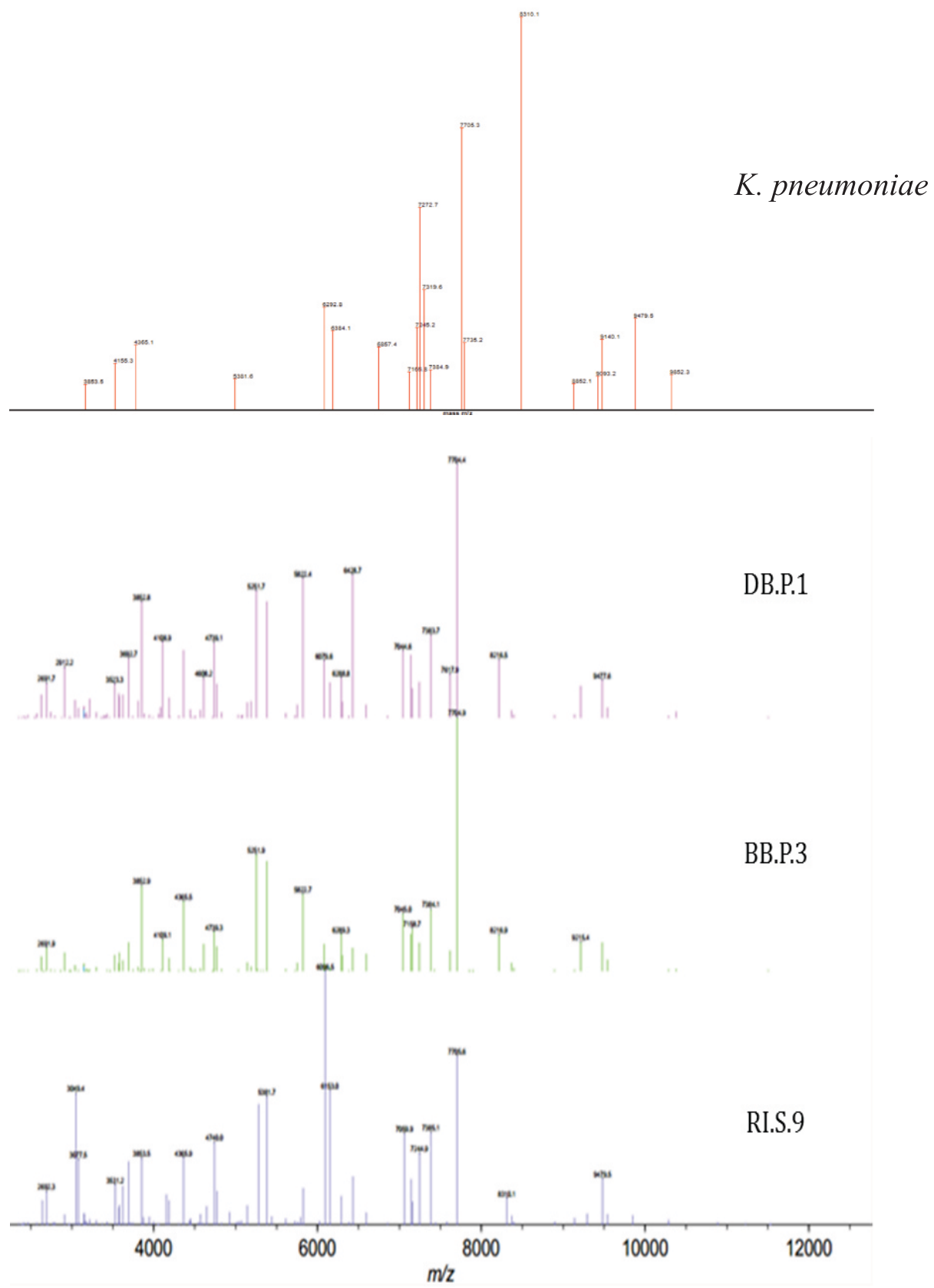

Figure 1 Spectral profiles of three isolates K. pneumoniae obtained from different part of white turmeric plant. These mass signals spectra $(3,853 ; 4,365 ; 6,292 ; 7,245 ; 7,384 ; 7,705 ; 9,140 ;$ and $9,479 \mathrm{~m} / \mathrm{z})$ are specific to K. pneumoniae. 
reference method. The results of MALDI-TOF MS analysis are indicated in percentages of similarity compared to spectra profiles of known strain in SARAMIS Database System. Superspectra contain common peaks to differentiate strains of the same species. Individual spectra corresponded to the spectra of each strain cultivated under specific conditions. The manufacturer recommends validation of superspectra identifications with the confidence level between 85.00 and $99.9 \%$. Accuracy of the identification strongly relies upon the robustness of the database and the choice of reference isolates. This is especially important when the genera involving species of environmental and clinical samples represents a high genetic diversity (Benagli et al. 2012).

The spectra were analysed in a mass range of 2 to $20 \mathrm{kDa}$ and this mass range representing ribosomal proteins were obtained from bacterial extract. These proteins are numerous in the cell and are positively charged. Fig. 1 shows the representative results of spectral profiles from Klebsiella pneumonia based on the mass signals obtained. Isolated bacteria from different part of plant (rhizome, stem, leaves) and locations (Darmaga and Bojong) showed similar identification due to their identical protein profiles which were indicated by mass spectra value. Three isolates of $K$. pneumoniae isolated from rhizome, stem and leaves of $C$. zedoaria plant showed almost the same spectral profiles. It had several specific mass signals 3,$853 ; 4,365 ; 6,292$; 7,245; 7,384; 7,705; 9,140; and 9,479 m/z. Each mass signal is specific at species and family level. Mass signal of 3,$853 ; 6,292 ; 7,384 ; 7,705$; and $9,479 \mathrm{~m} / \mathrm{z}$ were specific for species level, while 4,$365 ; 7,245 ; 9,140 \mathrm{~m} / \mathrm{z}$ were specific for family level. According to these results, it is clear that each species of bacteria has specific mass spectra, and can be used as a taxonomic marker identification. Compared with the data presented in Table 1, these mass signals correspond to the superspectrum database of K. pneumoniae.

The identification results obtained by MALDI-TOF MS and 16S rRNA gene sequencing of 66 isolates are shown in Table 2. Forty-three (43) of the 66 isolates $(65.15 \%)$ showed the intepretable MALDI-TOF MS spectra. By sequence comparison analysis, MALDI-TOF MS spectra allowed good identification to the species, genus and family level with a total of 43 endophytic bacteria covering 16 genus and 21 species. An additional 11 isolates $(16.67 \%)$ gave similar results with the sequencing results, and correctly identified to the

Table 1 Superspectrum database of K. pneumoniae

\begin{tabular}{cl}
\hline Mass $(\mathrm{m} / \mathbf{z})$ & Identification level \\
\hline $\mathbf{3 8 5 3 . 5}$ & Species level \\
4155.3 & Species level \\
$\mathbf{4 3 6 5 . 1}$ & Familylevel \\
5381.6 & Family level \\
$\mathbf{6 2 9 2 . 8}$ & Species level \\
6384.1 & Family level \\
6857.4 & Family level \\
7165.8 & Family level \\
7245.2 & Familylevel \\
7272.7 & Family level \\
7319.6 & Family level \\
$\mathbf{7 3 8 4 . 9}$ & Species level \\
$\mathbf{7 7 0 5 . 3}$ & Species level \\
7735.2 & Species level \\
8310.1 & Family level \\
8852.1 & Family level \\
9093.2 & Species level \\
$\mathbf{9 1 4 0 . 1}$ & Familylevel \\
$\mathbf{9 4 7 9 . 5}$ & Species level \\
9852.3 & Species level \\
\hline &
\end{tabular}


Table 2 Identification results for the 66 isolates obtained by MALDI-TOF MS in comparison to those obtained by $16 \mathrm{~S}$ rDNA

\begin{tabular}{|c|c|c|c|c|}
\hline \multirow{2}{*}{$\begin{array}{l}\text { Level of } \\
\text { ID and } \\
\text { isolates }\end{array}$} & \multicolumn{2}{|c|}{ 16S rDNA sequencing } & \multicolumn{2}{|l|}{ MALDI-TOF MS } \\
\hline & Species ID & $\begin{array}{l}\text { Level of } \\
\text { ID }\end{array}$ & Species ID & $\begin{array}{c}\text { Reference } \\
\text { database }\end{array}$ \\
\hline \multicolumn{5}{|c|}{ Correctly identified into species level } \\
\hline DI.P.3 & Alcaligenes faecalis & Species & Alcaligenes faecalis & A \\
\hline RB.P.1 & Bacillus subtilis & Species & Bacillus subtilis & A \\
\hline RL.S.2 & Enterobacter aerogenes & Species & Enterobacter aerogenes & A \\
\hline RI.P.2 & Enterobacter cloacae & Species & Enterobacter cloacae & A \\
\hline BB.P.3 & Klebsiella pneumoniae & Species & Klebsiella pneumoniae & $\mathrm{A}$ \\
\hline RI.S.2 & Klebsiella pneumoniae & Species & Klebsiella pneumoniae & $\mathrm{A}$ \\
\hline RI.S.9 & Klebsiella pneumoniae & Species & Klebsiella pneumoniae & A \\
\hline RI.P.3 & Pantoea dispersa & Species & Pantoea dispersa & $\mathrm{A}$ \\
\hline DB.S.1 & Pseudomonas stutzeri & Species & Pseudomonas stutzeri & $\mathrm{A}$ \\
\hline RB.P.4 & Pseudomonas stutzeri & Species & Pseudomonas stutzeri & A \\
\hline RI.P.7 & Stenotrophomonas maltophilia & Species & Stenotrophomonas maltophilia & $\mathrm{A}$ \\
\hline \multicolumn{5}{|c|}{ Correctly identified into genus level } \\
\hline RI.S.3 & Acinetobacter calcoaceticus & Genus & Acinetobacter baumannii & A \\
\hline DL.P.5 & Bacillus safensis & Genus & Bacillus pumilus & NA \\
\hline RI.P.5 & Bacillus thuringiensis & Genus & Bacillus cereus/ mycoides/thuringiensis & A \\
\hline RI.P.1 & Burkholderia cenocepacia & Genus & Burkholderia sp. & $\mathrm{A}$ \\
\hline DI.P.1 & Enterobacter cancerogenus & Genus & Enterobacter sp. & $\mathrm{A}$ \\
\hline DL.P.4 & Enterobacter cancerogenus & Genus & Enterobacter cloacae & A \\
\hline RI.P.8 & Enterobacter ludwigii & Genus & Enterobacter sp. & NA \\
\hline BI.P.3 & Enterobacter ludwigii & Genus & Enterobacter sp. & NA \\
\hline DB.P.1 & Klebsiella pneumoniae & Genus & Enterobacteriaceae & $\mathrm{A}$ \\
\hline RB.P.2 & Klebsiella pneumoniae & Genus & Enterobacteriaceae & $\mathrm{A}$ \\
\hline DI.P.4 & Klebsiella variicola & Genus & Klebsiella pneumoniae & NA \\
\hline RI.S.8 & Klebsiella variicola & Genus & Klebsiella pneumoniae & NA \\
\hline RB.S.3 & Klebsiella variicola & Genus & Enterobacteriaceae & NA \\
\hline BI.S.2 & Klebsiella variicola & Genus & Klebsiella pneumoniae & NA \\
\hline RI.P.4 & Microbacterium trichothecenolyticum & Genus & Microbacterium arborescens & NA \\
\hline DB.S.4 & Micrococcus yunnanensis & Genus & Micrococcus luteus & NA \\
\hline RI.S.7 & Pantoea agglomerans & Genus & Pantoea dispersa & $\mathrm{A}$ \\
\hline RI.S.6 & Pseudomonas azotoformans & Genus & Pseudomonas fluorescens & NA \\
\hline RB.P.3 & Pseudomonas denitrificans & Genus & Pseudomonasnitroreducens & NA \\
\hline DL.P.3 & Pseudomonas denitrificans & Genus & Pseudomonas nitroreducens & NA \\
\hline DB.S.3 & Psendomonas gessardii & Genus & Pseudomonas fluorescens & NA \\
\hline DI.S.1 & Pseudomonas korensis & Genus & Pseudomonas aeruginosa & $\mathrm{NA}$ \\
\hline DI.S.6 & Pseudomonas korensis & Genus & Pseudomonas sp. & NA \\
\hline \multicolumn{5}{|c|}{ Not precisely identified } \\
\hline BB.S.8 & Bacillus subtilis & & Lysinibacillus sphaericus & $\mathrm{A}$ \\
\hline BI.S.3 & Citrobacter freundii & & Enterobacter sp. & $\mathrm{A}$ \\
\hline DI.S.4 & Microbacterium laevaniformans & & Klebsiella pneumoniae & $\mathrm{A}$ \\
\hline BI.S.6 & Microbacterium laevaniformans & & Arthrobacter russicus & $\mathrm{A}$ \\
\hline BI.P.1 & Microbacterium resistens & & Pseudomonas aeruginosa & A \\
\hline DI.S.7 & Microbacterium testaceum & & Oligella urethralis & $\mathrm{A}$ \\
\hline BB.S.3 & Microbacterium trichothecenolyticum & & Gordonia alkanivorans & NA \\
\hline RI.P.6 & Pseudomonas geniculata & & Stenotrophomonas maltophilia & NA \\
\hline BI.S.1 & Ralstonia mannitolilytica & & Rhizobium radiobacter & A \\
\hline \multicolumn{5}{|c|}{ Not identified yet } \\
\hline DB.P.2 & Agrobacterium larrymoorei & & No ID & $\mathrm{NA}$ \\
\hline DL.P.6 & Bacillus subtilis & & No ID & $\mathrm{A}$ \\
\hline BL.P.2 & Bacillus subtilis & & No ID & $\mathrm{A}$ \\
\hline RL.S.1 & Bacillus safensis & & No ID & NA \\
\hline RB.S.5 & Bosea thiooxidans & & No ID & NA \\
\hline RB.S.2 & Enterobacter ludwigii & & No ID & $\mathrm{NA}$ \\
\hline BB.P.4 & Erwinia chrysanthemi & & No ID & NA \\
\hline DL.S.1 & Methylobacterium organophilum & & No ID & NA \\
\hline BB.S.5 & Microbacterium hominis & & No ID & $\mathrm{NA}$ \\
\hline
\end{tabular}


Table 2 Continued

\begin{tabular}{|c|c|c|c|c|}
\hline \multirow{2}{*}{$\begin{array}{l}\text { Level of } \\
\text { ID and } \\
\text { isolates }\end{array}$} & \multicolumn{2}{|c|}{ 16S rDNA sequencing } & \multicolumn{2}{|c|}{ MALDI-TOF MS } \\
\hline & Species ID & $\begin{array}{l}\text { Level of } \\
\text { ID }\end{array}$ & Species ID & $\begin{array}{c}\text { Reference } \\
\text { database }\end{array}$ \\
\hline \multicolumn{5}{|c|}{ Correctly identified into species level } \\
\hline DB.S.2 & Microbacterium laevaniformans & & No ID & $\mathrm{A}$ \\
\hline BI.P.6 & Microbacterium laevaniformans & & No ID & A \\
\hline DI.S.2 & Microbacterium resistens & & No ID & A \\
\hline DI.S.3 & Microbacterium testacneum & & No ID & A \\
\hline DL.P.1 & Microbacterium testaceum & & No ID & $\mathrm{A}$ \\
\hline BL.S.2 & Mycobacterium cosmeticum & & No ID & NA \\
\hline BB.S.6 & Mycobacterium simiae & & No ID & $\mathrm{A}$ \\
\hline RL.P.4 & Phenylobacterium koreense & & No ID & NA \\
\hline RL.P.1 & Providencia vermicola & & No ID & NA \\
\hline DI.S.5 & Rhizobium tarimense & & No ID & NA \\
\hline RL.S.3 & Roseomonas mucosa & & No ID & NA \\
\hline BL.P.1 & Stenotrophomonas maltophila & & No ID & $\mathrm{A}$ \\
\hline DL.P.2 & Stenotrophomonas maltophila & & No ID & $\mathrm{A}$ \\
\hline BB.S.7 & Xanthobacter flavus & & No ID & NA \\
\hline
\end{tabular}

Note: A: Available; NA: Not Available

species level; 23 isolates $(34.85 \%)$ matched genus level of molecular approach, and among them 3 isolates were identified to the family level. For three isolates (DB.P.1, RB.P.2, RB.S.3), MALDITOF MS correctly identified to the family level, whereas $16 \mathrm{~S}$ rDNA sequencing gave a species identification. Nine isolates $(13.64 \%)$ were not accurately identified and 23 isolates $(34.85 \%)$ were rated as non-identifiable (Table 3 ).

This study has proved that MALDI-TOF MS is useful for identification of microorganisms into species level in a relatively short time. Of the 66 isolates analyzed, 43 isolates $(65.15 \%)$ were identified and 23 isolates $(34.85 \%)$ were not identified (Table 3). Eleven isolates $(16.67 \%$ ) of 43 isolates showed good result, concordant with the 16S rDNA sequencing result. However, twenty-three isolates $(34.85 \%)$ could not be identified. These included 12 isolates of Microbacterium genus, Mycobacterium cosmeticum, Mycobacterium simiae, Agrobacterium larrymoorei, Erwinia chrysanthemi, Xanthobacter flavus, Enterobacter ludwigii, Bosea thiooxidans, Stenotrophomonas maltophilia, Methylobacterium organophilum, Providencia vermicola, Phenylobacterium koreense, Bacillus safensis,
Roseomonas mucosa, Rhizobium tarimense. Among them, 14 isolates could not be identified due to the absence of reference spectra database.

Non-identifiable isolates for MALDI-TOF was as a result of an incomplete database, and can be resolved with the addition of appropriate reference. Supplementation of the MALDI-TOF database, can reduce the rate of non-identifiable results. Among 66 isolates of endophytic bacteria, 30 isolates had no reference spectra database (Table 3). Currently, a total of 1,309 references spectra are contained in SARAMIS Database System. This is inadequate to identify indigenous microbes that have been abundant in Indonesia. MALDI-TOF MS library can be enriched with protein profile of strain or species of indigenous microbes from Indonesia, and will be important for future studies.

MALDI-TOF MS generates protein mass spectra which can be used for grouping and identification of bacteria. These mass spectra contain mainly peaks corresponding to ribosomal protein that are in abundance in the bacterial cell (Rhyzhov \& Fenselau 2001). Protein profile of mass spectra will help in characterizing the

Table 3 Distribution of the discrepancies observed in the MALDI-TOF MS Axima-SARAMIS

\begin{tabular}{lccc}
\hline \multirow{2}{*}{ Level of identification by MALDI-TOF MS } & \multicolumn{2}{c}{ No. (\%) of Reference database } \\
\cline { 2 - 4 } & Available & Not available & Total \\
\hline Correctly identified into species level & $11(16.67)$ & 0 & $11(16.67)$ \\
\hline Correctly identified into genus level & $8(12.12)$ & $15(22.73)$ & $23(34.85)$ \\
\hline Not precisely identified & $7(10.60)$ & $2(3.03)$ & $9(13.64)$ \\
\hline Not identified yet & $10(15.15)$ & $13(19.70)$ & $23(34.85)$ \\
\hline Total & $36(54.54)$ & $30(45.46)$ & 66 \\
\hline
\end{tabular}


incorrectly identified microbes by comparing its protein profile spectra to those in the reference spectra database. These spectra can generate patterns that provide unbiased identification of particular species and even genotypes within species. Data presented in Table 3, shows that 9 isolates were incorrectly identified. As stated earlier, each species of bacteria has specific protein profile mass spectra, therefore the identification result from MALDI-TOF MS should be same to the identification result of $16 \mathrm{~S}$ rDNA. The result will be incorrect when experimental factors occur, such as sample contamination and/or sample preparation.

MALDI-TOF MS analysis is affected by several experimental factors, such as matrix preparation, spectral reproducibility, contaminants, sample preparation, mass range and measurement accuracy on the database search (Demirev et al. 1999). A total of 12 isolates of Microbacterium genus were incorectly identified, might be due to the complex structure of their cell walls. Specific sample extraction procedures to breakdown the cell wall are required before MALDI-TOF MS analysis. The process of sample preparation for identification of microbes depends upon the source of isolated microbe, or on chemical structure of the constituents of its cell wall. Different group of microbes has different sample preparation (Singhal et al. 2015). Alatoom et al. (2011) reported that sample extraction was needed for identification of Grampositive bacteria. Furthermore, the lower score values, may be caused by the incomplete separation of protein. The protein interfered with the sample and disrupt the mass spectrum (Reich et al. 2013). Gram-positive bacteria like Mycobacterium sp., also require specific extraction procedure. The extraction was done by lysed cells in boiling water, followed by ethanol precipitation of proteins. The precipitated proteins were dried, resuspended in 70\% formic acid and acetonitrile, and analyzed by MALDI-TOF MS (Verroken $e t a l$. 2010).

To investigate the reproducibility of the instrument during the study, we included InaCC strains in every analysis of identifications as positive controls and reference isolates. The instruments correctly identified the control strains. The incorrect identification by MALDITOF MS was attributed to sample preparation failure such as large sample volume and also, the amount of matrix was not sufficient. Consequently the sample and matrix were not completely mixed and only a few small crystal were obtained. A sufficient number of bacterial cells (typically $\sim 10^{4}$ cells per well) are required to generate detectable MALDI-TOF MS ion signals (Chiu 2014).

Lohman et al. (2013) reported that MALDITOF system succesfully identified 312 isolates. Furthermore 2,860 of 2,900 (99\%) samples identified by MALDI-TOF MS matched with the identification results obtained using other methods (standard and high end microbiological identification methods including automated biochemical analyses and molecular identification) (Reich et al. 2013). Study of Guo et al. (2014) informed that using MALDI-TOF MS for 1,025 isolates, $1,021(99.60 \%)$ isolates were accurately identified at the genus level, and 957 $(93.37 \%)$ isolates at the species level. Theel et al. (2012) reported that from 90 yeast and 78 Corynebacterium species isolates, were obtained $95.6 \%$ and $81.1 \%$ of yeast, also $96.1 \%$ and $92.3 \%$ of Corynebacterium isolates were correctly identified to the genus and species levels, respectively. As compared to other studies, the result of this study showed small percentage of correctly identified to the genus and species levels, however this method provide reliable results. Therefore MALDI-TOF MS could be used for screening and grouping of large numbers of bacterial isolates. Microorganism identification by mass spectrometry is already considered as a revolution of bacteriology, offering many advantages compared with the conventional biochemical identification of microorganisms. Within the next few years MALDI-TOF-MS based identification of microorganisms will replace conventional methods.

\section{CONCLUSION}

Among the 66 selected isolates, 43 isolates were identified. Eleven isolates $(16.67 \%)$ that were tested matched on species level of molecular approach. Spectral analysis of microbial diversity from Indonesia is one way to build up the MALDI-TOF MS library. Protein profile spectra of each species could be used as ataxonomic marker. MALDI-TOF MS systems for bacterial 
identification was good for grouping large number of isolates. However molecular analysis also must be done as a standard reference. Combination of molecular analysis and protein profile using MALDI-TOF MS slightly accelerated the bacterial identification.

\section{ACKNOWLEDGEMENTS}

This project was fully supported by DIPA Tematik 2013, Research Center for Biology LIPI and JST-JICA. Special thanks to Sulistiani and all members of the Biosystematic Laboratory, Research Center for Biology, LIPI.

\section{REFERENCES}

Alatoom AA, Cunningham SA, Ihde SM, Mandrekar J, Patel R. 2011. Comparison of direct colony method versus extraction method for identification of grampositive cocci by use of bruker biotyper matrixassisted laser desorption ionization-time of flight mass spectrometry. J Clin Microbiol 49(8):2868-73. doi: 10.1128/JCM.00506-11

Benagli C, Demarta A, Caminada A, Ziegler D, Petrini O, Toolla M. 2012. A rapid MALDI-TOF MS identification database at genospecies level for clinical and environmental Aeromonas strains. PLoS ONE 7(10):e48441. doi: 10.1371/journal.pone. 0048441

Bizzini A, Jaton K, Romo D, Bille J, Prod'hom G, Greub G. 2011. Matrix-assisted laser desorption ionization-time of flight mass spectrometry as an alternative to $16 \mathrm{~S}$ rRNA gene sequencing for identification of difficult-to-identify bacterial strains. J Clin Microb 49(2):693-6. doi: 10.1128/JCM.01463-10

Cain TC, Lubman DM, Weber Jr WJ. 1994. Differentiation of bacteria using protein profiles from matrixassisted laser desorption/ionization time-of-flight mass spectrometry. Rapid Commun Mass Spectrom 8(12):1026-30.

Chiu TC. 2014. Review: Recent advances in bacteria identification by matrix-assisted laser desorption/ionization mass spectrometry using nanomaterials as affinity probes. Int $\mathrm{J}$ Mol Sci 15(5):7266-80. doi: 10.3390/ijms15057266

Demirev PA, Ho YP, Ryzhov V, Fenselau C. 1999. Microorganism identification by mass spectrometry and protein database searches. Anal Chem 71(14):2732-8.

Eigner U, Holfelder M, Oberdorfer K, Betz-Wild U, Bertsch D, Fahr AM. 2009. Performance of a matrix-assisted laser desorption ionizationtime-of-flight mass spectrometry system for the identification of bacterial isolates in the clinical routine laboratory. Clin Lab 55(7-8):289-96.

Ferroni A, Suarez S, Beretti JL, Dauphin B, Bille E, Meyer J, ... Nassif X. 2010. Real-time identification of bacteria and Candida species in positive blood culture broths by matrix-assisted laser desorption ionization-time of flight mass spectrometry. Am Soc Microbiol 48(5):1542-8

Guo L, Ye L, Zhao Q, Ma Y, Yang J, Luo Y. 2014. Comparative study of MALDI-TOF MS and VITEK 2 in bacteria identification. J Thorac Dis 6(5):534-8. doi: $10.3978 / j . i s s n .2072$ 1439.2014.02.18

Jamal WY, Ahmad S, Khan ZU, Rotimi VO. 2014. Comparative evaluation of two matrix-assisted laser desorption/ionization time-of-flight mass spectrometry (MALDI-TOF MS) systems for the identification of clinically significant yeasts International. Int J Infect Dis 26:167-70.

Kudirkiene E, Welker M, Knudsen NR, Bojesen AM. 2015. Rapid and accurate identification of Streptococcus equi subspecies by MALDI-TOF MS. Syst Appl Microbiol 38(5):315-22.

Lohmann C, Sabou M, Moussaoui W, Prévost G, Delarbre J, Candolfi E, ... Letscher-Brub V. 2013. Comparison between the Biflex III-Biotyper and the AximaSARAMIS systems for yeast identification by matrix-assisted laser desorption ionization-time of flight mass spectrometry. J Clin Microbiol 51(4):1231-6.

Martiny D, Busson L, Wybo I, El Haj RA, Dediste A, Vandenberg O. 2012. Comparison of the Microflex LT and Vitek MS systems for routine identification of bacteria by matrix-assisted laser desorption ionization time of flight mass spectrometry. J Clin Microbiol 50(4):1313-25.

Neville SA, Lecordier A, Ziochos H, Chater MJ, Gosbell IB, Maley MW, van Hal SJ. 2011. Utility of matrixassisted laser desorption ionization time of flight mass spectrometry following introduction for routine laboratory bacterial identification. J Clin Microbiol 49(8):2980-4.

Rajendhran P, Gunasekaran. 2011. Microbial phylogeny and diversity: small subunit ribosomal RNA sequence analysis and beyond. J Microbiol Res 166(2):99-110. doi: 10.1016/j.micres.2010.02.003

Reich M, Bosshard PP, Stark M, Beyser K, Borgmann S. 2013. Species identification of bacteria and fungi from solid and liquid culture media by MALDI TOF mass spectrometry. J Bacteriol Parasitol S5:002:1-8. doi: 10.4172/2155-9597.S5002

Rhyzhov V, Fenselau C. 2001. Characterization of the protein subset desorbed by MALDI from whole bacterial cells. Anal Chem 73(4):746-50. 
Rychert J, Burnham CA, Bythrow M, Garner OB, Ginocchio CC, Jennemann R, ... Branda JA. 2013. Multicenter evaluation of the Vitek MS matrixassisted laser desorption ionization-time of flight mass spectrometry system for identification of gram-positive aerobic bacteria. J Clin Microbiol 51(7):2225-31. doi: 10.1128/JCM.00682-13

Santos FS, Cayo R, Schandert L, Gales AC. 2013. Evaluation of MALDI-TOF MS in the microbiology laboratory. J Bras Patol Med Lab 49(3):191-7.

Seng P, Drancourt M, Gouriet F, La Scola B, Fournier P, Rolain JM, Raoult D. 2009. Ongoing revolution in bacteriology: routine identification of bacteria by matrix-assisted laser desorption ionization time-offlight mass spectrometry. Clin Infect Dis 49(4):54351.

Singhal N, Kumar M, Kanaujia PK, Virdi JS. 2015. MALDITOF mass spectrometry: An emerging technology for microbial identification and diagnosis. Front Microbiol 6:791-806. doi: 10.3389/fmicb.2015. 00791

Sulistiyani TR, Lisdiyanti P, Lestari Y. 2014. Population and diversity of endophytic bacteria associated with medicinal plant Curcuma zedoaria. Microbiol Ind 8(2):65-72. doi: 10.5454/mi.8.2.4

Theel ES, Schmitt BH, Hall L, Cunningham SA, Walchak RC, Patel R, Wengenacka NL. 2012. Formic acidbased direct, on-plate testing of yeast and Corynebacterium species by Bruker biotyper matrixassisted laser desorption ionization-time of flight mass spectrometry. J Clin Microb 50(9):3093-5.

Verroken A, Janssens M, Berhin C, Bogaerts P, Huang TD, Wauters G, Glupczynski Y. 2010. Evaluation of matrix-assisted laser desorption ionization-time of flight mass spectrometry for identification of Nocardia species. J Clin Microbiol 48(11):4015-21.

Woo PCY, Lau SKP, Teng JLL, Tse H, Yuen KY. 2008. Then and now: Use of $16 \mathrm{~S}$ rDNA gene sequencing for bacterial identification and discovery of novel bacteria in clinical microbiology laboratories. Clin Microbiol Infect 14(10):908-34.

Wunschel SC, Jarman KH, Petersen CE, Valentine NB, Wahl KL, Schauki D, ... White VE. 2005. Bacterial analysis by MALDI-TOF mass spectrometry: An inter-laboratory comparison. J Am Soc Mass Spectrom 16(4):456-62. doi: org/10.1016/j.jasms. 2004.12.004 